\title{
Observation of Phosphorylation Site-Specific Dissociation of Singly Protonated Phosphopeptides
}

\author{
Young Sik Shin, ${ }^{\mathrm{a}}$ Jeong Hee Moon, ${ }^{\mathrm{b}}$ and Myung Soo Kim ${ }^{\mathrm{a}}$ \\ a Department of Chemistry, Seoul National University, Seoul, Korea \\ ${ }^{\mathrm{b}}$ Medical Proteomics Research Center, KRIBB, Daejeon, Korea
}

In ultraviolet photodissociation of phosphopeptide ions with a basic residue (arginine, lysine, or histidine) at the N-terminus, intense $\mathrm{a}_{\mathrm{n}}-97$ peaks were observed. These ions were formed by cleavage at phosphorylated residues only. For multiply phosphorylated peptides, this site-specific cleavage occurred at every phosphorylated residue. $\mathrm{H} / \mathrm{D}$ exchange studies showed that $\mathrm{a}_{\mathrm{n}}-97$ was formed by $\mathrm{H}_{3} \mathrm{PO}_{4}$ loss from $\mathrm{a}_{\mathrm{n}}+1$ radical cations. The site-specificity of phosphate loss observed here is in contrast to the nonspecific phosphate loss from $b_{n}$ and $\mathrm{y}_{\mathrm{n}}$ reported previously. Characteristics of the reaction and its potential utility for phosphopeptide analysis are discussed. (J Am Soc Mass Spectrom 2010, 21, 53-59) (C) 2010 American Society for Mass Spectrometry

$\mathrm{T}$ landem mass spectrometry [1-3] is widely used for structural and mechanistic studies of protonated peptides generated by matrix-assisted laser desorption ionization (MALDI) [4] and electrospray ionization (ESI) [5]. The internal energy acquired by a precursor ion at the time of its formation can be the driving force for its dissociation such as in post-source decay (PSD) [6]. Dissociation can be further enhanced by using ion activation techniques such as collisionally activated dissociation (CAD) [3, 7], ultraviolet photodissociation (UV-PD) [8, 9], electron capture dissociation (ECD) [10], and electrontransfer dissociation (ETD) [11].

Tandem mass spectra for singly protonated peptides- to be called peptide ions-are dominated by $b$ and y type product ions (see references [12] and [13] for fragment ion notation) and their consecutive dissociation products. Notable exceptions are the spectra for peptide ions with arginine recorded at high internal energy such as in high-energy CAD and UV-PD. Here, new series of sequence ions, viz. $\left(a_{n}, d_{n}\right)$ or $\left(x_{n}, v_{n}, w_{n}\right)$ for peptide ions with arginine at the $\mathrm{N}$ - or $\mathrm{C}$-termini, respectively, become dominant. Biemann [13] suggested that dissociation at high internal energy is initiated by $\mathrm{C}_{\alpha}-\mathrm{CO}$ homolytic cleavage, generating $a_{n}+1$ or $x_{n}+1$ radical cations when arginine is at the $\mathrm{N}$ - or C-terminus, respectively. $\mathrm{a}_{\mathrm{n}}+1$ is thought to further dissociate to $a_{n}$ and $d_{n}$, and $x_{n}+1$ to $x_{n}$ $\mathrm{v}_{\mathrm{n}}$, and $\mathrm{w}_{\mathrm{n}}$.

Phosphorylation of serine $(\mathrm{S})$, threonine $(\mathrm{T})$, and tyrosine $(\mathrm{Y})$ residues in proteins is the key mode of signal transduction and amplification for eukaryotes $[14,15]$. Even though ECD and ETD are regarded as the most powerful mass spectrometric techniques for phos-

Address reprint requests to Professor M. S. Kim, Department of Chemistry, Seoul National University, Seoul 151-742, Korea. E-mail: myungsoo@snu.ac.kr phoprotein and phosphopeptide analysis, other techniques such as PSD and CAD are also used [16-19]. One of the main problems with the latter techniques is that intact sequence ions such $a b_{n}$ and $y_{n}$ are often missing or appear weakly for S/T-phosphorylated peptide ions. Instead, dephosphorylated sequence ions such as $b_{n}$ $\mathrm{H}_{3} \mathrm{PO}_{4}$ and $\mathrm{y}_{\mathrm{n}}-\mathrm{H}_{3} \mathrm{PO}_{4}$ appear prominently [20].

Recently, we studied dissociation of phosphopeptide ions using photodissociation multi-stage $\left(\mathrm{MS}^{n}\right)$ time-offlight (TOF) mass spectrometry [21]. Through reaction intermediate monitoring with $\mathrm{PD}-\mathrm{MS}^{3}$, dephosphorylated sequence ions were found to be formed by consecutive reactions mainly via the corresponding intact sequence ions, e.g., $\mathrm{MH}^{+} \rightarrow \mathrm{b}_{\mathrm{n}} \rightarrow\left[\mathrm{b}_{\mathrm{n}}-\mathrm{H}_{3} \mathrm{PO}_{4}\right]^{+}$. The second step of such a reaction, viz. dephosphorylation, was found to occur regardless of the position of the phosphorylated residue. Hence, even though the appearance of $\left[b_{n}-H_{3} P_{4}\right]^{+}$is an indication that $b_{n}$ is a phosphorylated sequence ion, it alone is not useful in pinpointing the position of the phosphorylated residue.

In PD-MS ${ }^{2}$ spectra for phosphopeptide ions with a basic residue at the $\mathrm{N}$-terminus, we observed some prominent peaks assignable to $a_{n}-97$. Investigation for a variety of phosphopeptides utilizing $\mathrm{H} / \mathrm{D}$ exchange has found that these peaks are formed by $\mathrm{H}_{3} \mathrm{PO}_{4}$ loss from $a_{n}+1$, which, in turn, is formed by $\mathrm{C}_{\alpha}-\mathrm{CO}$ cleavage of peptide ions. More importantly, $a_{n}-97$ has been found to form only when the phosphate group is at the C-terminal of $a_{n}+1$, a case of site-specific reaction. The results are reported in this article.

\section{Experimental}

A homebuilt MALDI-PD tandem TOF was used to record PSD and PD spectra of phosphopeptide ions. 
Details of the apparatus and its operation were reported previously $[22,23]$. MALDI was done with a nitrogen laser (MNL205-C; Lasertechnik, Berlin, Germany), using 2,5-dihydroxybenzoic acid (DHB) as the matrix. 193 nm output of an excimer laser (PSX-100; MPB Communication Inc., Montreal, Quebec, Canada) or $266 \mathrm{~nm}$ output of an Nd:YAG laser (Surelite III-10; Continuum, Santa Clara, CA, USA) was used for PD. A PD laser pulse was synchronized with the lowest mass isotopomer pulse of a precursor ion. A laser-off spectrum (PSD) was subtracted from a laser-on spectrum to get a PD spectrum.

\section{Samples}

Phosphopeptides used in this work (RTpTST, RApSPVA, RRApSVA, HTpTTT, KApSpSSG, KApSSSG, HTpTTTK, HTpTTTR, RGpTpTIT, and RLpTpSTpSSF) were purchased from Peptron (Daejeon, Korea). Other chemicals, including the matrix (DHB), were purchased from Sigma (St. Louis, MO, USA). The method to prepare MALDI samples was the same as described previously [24]. The method for H/D exchange was also reported previously [25].

\section{Results}

$[R T p T S T+H]^{+} . \quad$ PSD and $193 \mathrm{~nm}$ PD spectra for this peptide ion are shown in Figure 1. Identities of the product ions, which are consistent with the H/D exchange results, are marked in the figure.

In PSD spectrum, $\left[\mathrm{M}+\mathrm{H}-\mathrm{H}_{3} \mathrm{PO}_{4}\right]^{+}$is the most intense product ion. $\left[\mathrm{M}+\mathrm{H}-\mathrm{HPO}_{3}\right]^{+}$appears less prominently, in agreement with a previous report for S/T-phosphorylated peptide ions [17]. Other product ions formed by small neutral loss are $\left[\mathrm{M}+\mathrm{H}-\mathrm{H}_{2} \mathrm{O}\right]^{+}$, $\left[\mathrm{M}+\mathrm{H}-2 \mathrm{H}_{2} \mathrm{O}\right]^{+}$, and $\left[\mathrm{M}+\mathrm{H}-\mathrm{H}_{3} \mathrm{PO}_{4}-\mathrm{H}_{2} \mathrm{O}\right]^{+}$. The peak at $m / z 503.2$ can be assigned to $\left[\mathrm{M}+\mathrm{H}-\mathrm{H}_{3} \mathrm{PO}_{4}-\right.$ $\left.\mathrm{R}_{\mathrm{T}}\right]^{+}$, in which $\mathrm{R}_{\mathrm{T}}$ is the threonine side chain [26]. $b_{n}$ $(n=1-4)$ ions are the most prominent sequence ions. They are accompanied by $\mathrm{H}_{3} \mathrm{PO}_{4}$ loss peaks, $\mathrm{b}_{\mathrm{n}}{ }^{*}(n=3$, $4)$, and CO loss peaks, $\mathrm{a}_{\mathrm{n}}(n=1-3)$. (In this work, the superscripts * and ${ }^{\circ}$ will be used to denote product ions with $\mathrm{H}_{3} \mathrm{PO}_{4}$ and $\mathrm{HPO}_{3}$ losses, respectively. Multiple superscripts indicate multiple neutral losses. For example, ${ }^{* *}$ and ${ }^{* \circ}$ denote ions with $2 \mathrm{H}_{3} \mathrm{PO}_{4}$ and $\mathrm{H}_{3} \mathrm{PO}_{4}+$ $\mathrm{HPO}_{3}$ losses, respectively.) Due to the presence of arginine at the $\mathrm{N}$-terminus, sequence ions with charge retention at the $\mathrm{C}$-terminus such as $\mathrm{y}_{\mathrm{n}}$ are hardly observed.

Product ions appearing in PD spectrum (Figure 1b) are rather similar to those in PSD. $\left[\mathrm{M}+\mathrm{H}-\mathrm{H}_{2} \mathrm{O}\right]^{+}$in this spectrum appears as a negative peak because its intensity in the laser-on spectrum is weaker than in the laser-off spectrum (PSD). This can occur when $[\mathrm{M}+$ $\left.\mathrm{H}-\mathrm{H}_{2} \mathrm{O}\right]^{+}$undergoes PD itself; PSD product ions move with the same velocity as their precursor ion. We have mentioned earlier that $\mathrm{C}_{\alpha}-\mathrm{CO}$ homolytic cleavage to $a_{n}+1$ and its further dissociation to $a_{n}$ and $d_{n}$ are characteristic high-energy channels for peptide ions with arginine at the $\mathrm{N}$-terminus. In agreement with this spectral correlation, $\mathrm{a}_{\mathrm{n}}+1(n=1,2)$ and $\mathrm{d}_{\mathrm{na}}(n=2,3)$ are present in PD spectrum. Here, $d_{n a}$ represents $d_{n}$ formed by OX $\left(X=H\right.$ or $\left.\mathrm{PO}(\mathrm{OH})_{2}\right)$ loss from $\mathrm{a}_{\mathrm{n}}+1$. Even though $\mathrm{a}_{\mathrm{n}}(n=1-3)$ ions also appear in the spectrum, it is not certain whether each $a_{n}$ is formed via

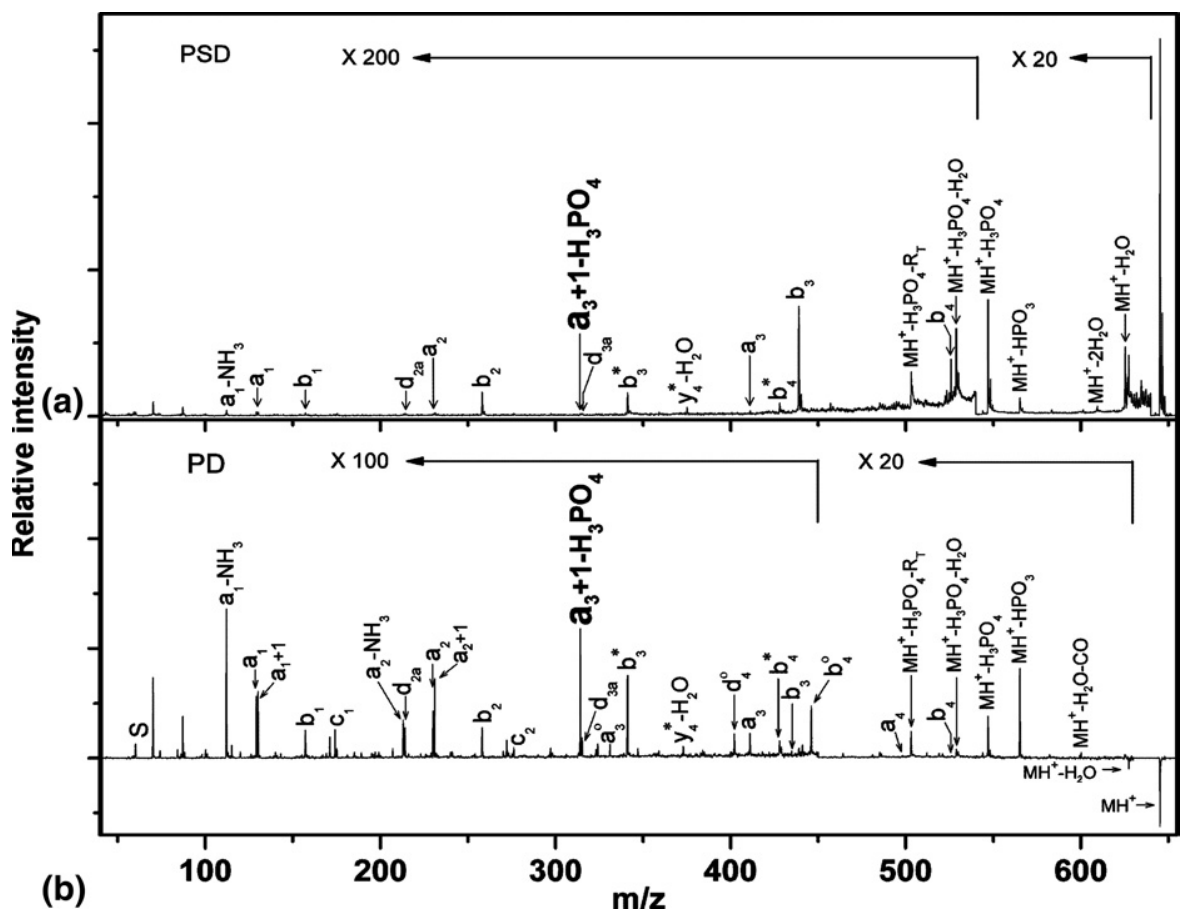

Figure 1. (a) PSD and (b) $193 \mathrm{~nm}$ PD spectra of [RTpTST $+\mathrm{H}]^{+}$formed by DHB-MALDI. Identities of product ions consistent with $\mathrm{H} / \mathrm{D}$ exchange results are marked. 
$\mathrm{a}_{\mathrm{n}}+1$ because a product ion with the same chemical composition, but probably with a different structure, can also be formed by $\mathrm{CO}$ loss from $b_{n}$ [27]. Let us denote these two different $a_{n}$ ions, those from $a_{n}+1$ and $b_{n}$, as $a_{n}^{h}$ and $a_{n}^{\ell}$, respectively. Generation of $a_{n}^{h}$ from $a_{n}+1$ is shown in Scheme 1. $a_{n}^{h}$ and $a_{n}^{\ell}$ can be distinguished by $\mathrm{H} / \mathrm{D}$ exchange because the hydrogen lost in the formation of the latter is exchangeable while that of the former is not [25]. Splitting of the $a_{2}$ peak in PD into $a_{2}^{\ell}$ and $a_{2}^{h}$ upon H/D exchange is shown in Figure 2a. Even though $\mathrm{a}_{2}^{h}$ is weaker than $\mathrm{a}_{2}^{\ell}$ in this case, strong intensity of $\mathrm{a}_{2}+1$ suggests that the high-energy dissociation channel is competing effectively with the low-energy one.

There was one strong peak in PD spectrum that could not be easily assigned, viz. the peak at $m / z$ 314.2. After checking various possible chemical compositions with the mass $314.2 \mathrm{Da}$, we concluded that it was probably $a_{3}-97$. If the ion is formed via loss of 97-the most likely candidate for 97 is $\mathrm{NH}_{3}+\mathrm{HPO}_{3}$-from $\mathrm{a}_{3}$, there are two possibilities for $\mathrm{a}_{3}-97$, namely $\mathrm{a}_{3}^{\ell}-$ $\mathrm{NH}_{3}-\mathrm{HPO}_{3}$ and $\mathrm{a}_{3}^{h}-\mathrm{NH}_{3}-\mathrm{HPO}_{3}$. They will be called Structures 1 and 2, respectively. Alternatively, $\mathrm{a}_{3}-97$ may actually be $\mathrm{a}_{3}+1-98$, viz. $\mathrm{a}_{3}+1-\mathrm{H}_{3} \mathrm{PO}_{4}$ (or, might be $\left.\mathrm{a}_{3}+1-\mathrm{HPO}_{3}-\mathrm{H}_{2} \mathrm{O}\right)$. In our attempt to distinguish the three cases by $\mathrm{H} / \mathrm{D}$ exchange, we realized that upon $\mathrm{H} / \mathrm{D}$ exchange, $\mathrm{a}_{3}+1$ might lose either $\mathrm{D}_{3} \mathrm{PO}_{4}$ or $\mathrm{HD}_{2} \mathrm{PO}_{4}$-two hydrogens in the phosphate group, $\mathrm{OPO}(\mathrm{OH})_{2}$, are exchangeable. Even though we do not know the structures of the product ions formed by $\mathrm{D}_{3} \mathrm{PO}_{4}$ or $\mathrm{HD}_{2} \mathrm{PO}_{4}$ losses, they will be called Structures 3 and 4 , respectively. Upon H/D exchange, the $\mathrm{m} / \mathrm{z}$ ratios of the structures $1,2,3$, and 4 become 321.2, $322.2,323.3$, and 324.3, respectively, and hence can be distinguished. The $a_{3}-97$ region in $193 \mathrm{~nm} \mathrm{PD}$ spectrum of [RTpTST $+\mathrm{H}^{+}$after $\mathrm{H} / \mathrm{D}$ exchange is shown in Figure $2 b$. Clearly $\mathrm{a}_{3}+1-\mathrm{D}_{3} \mathrm{PO}_{4}$, i.e., Structure 3 , is the main contributor to the original $\mathrm{a}_{3}-$ 97 peak, even though other structures also contribute.

It is to be emphasized that $\mathrm{a}_{4}-97$ does not appear in PD spectrum $\left(a_{1}-97\right.$ and $a_{2}-97$ cannot be formed because neither $a_{1}+1$ nor $a_{2}+1$ contains a phosphate group). This suggests that $a_{n}-97$ is generated only from $\mathrm{a}_{\mathrm{n}}+1$ formed by $\mathrm{C}_{\alpha}-\mathrm{CO}$ cleavage at the $\mathrm{C}$ terminal of the phosphorylated residue (for brevity, this will be called $\mathrm{C}_{\alpha}-\mathrm{CO}$ cleavage at the phosphorylated residue). It is to be mentioned that $a_{3}-97$ appears in PSD spectrum (Figure 1a) also, even though as an extremely weak peak. Finally, it is to be mentioned that
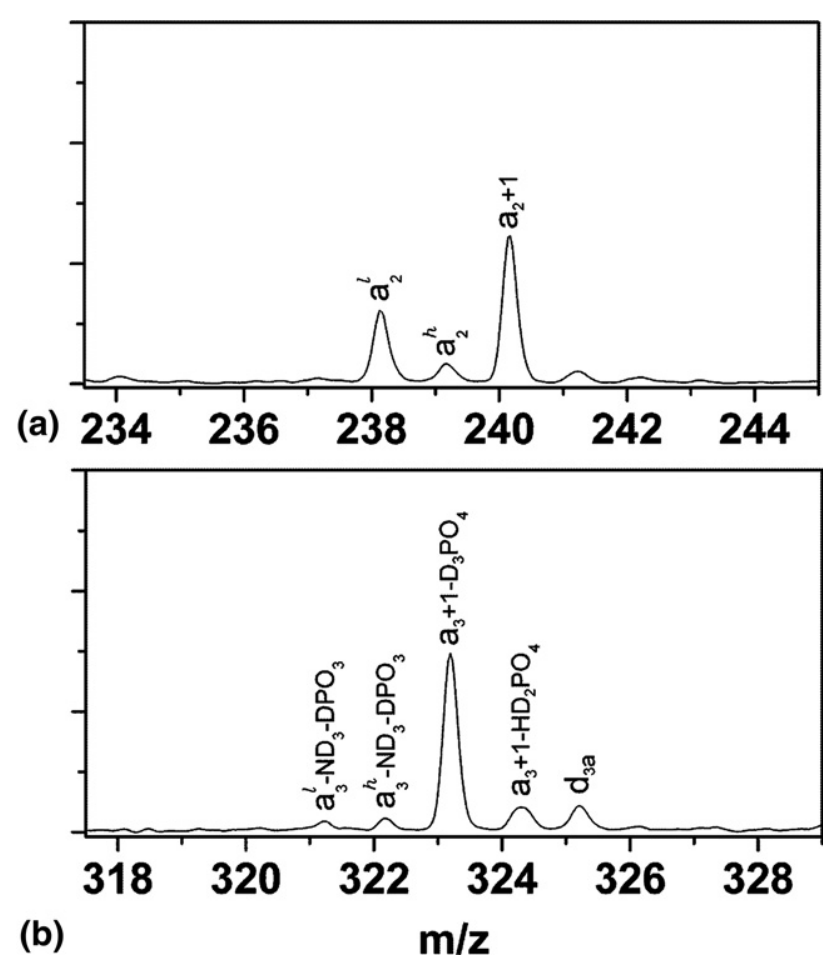

Figure 2. (a) $\mathrm{a}_{2}$ and (b) $\mathrm{a}_{3}-97$ spectral regions of $193 \mathrm{~nm}$ PD spectrum of [RTpTST $+\mathrm{H}]^{+}$after H/D exchange. The extent of $\mathrm{H} / \mathrm{D}$ exchange for the precursor ion estimated from its isotopic pattern in MALDI spectrum was $98.5 \%$.

the trend found for [RTpTST $+\mathrm{H}]^{+}$was also observed for other peptide ions with arginine at the $\mathrm{N}$-terminus investigated in this work, viz. [RApSPVA $+\mathrm{H}]^{+}$and $[\mathrm{RRApSVA}+\mathrm{H}]^{+}$(PD spectra in the Supplemental Data, which can be found in the electronic version of this article).

\section{$[R G p T p T I T+H]^{+}$and $[R L p T p S T p S S F+H]^{+}$}

One hundred ninety-three nm PD spectra of these peptide ions are shown in Figure 3. The peaks at $m / z$ 270.1 and 451.0 in PD spectrum for [RGpTpTIT $+\mathrm{H}^{+}$ (Figure 3a) are due to $\mathrm{a}_{3}+1-\mathrm{H}_{3} \mathrm{PO}_{4}$ and $\mathrm{a}_{4}+1-$ $\mathrm{H}_{3} \mathrm{PO}_{4}$, respectively, as confirmed through $\mathrm{H} / \mathrm{D}$ exchange. It is to be noted that $a_{5}-97$, that cannot be formed by the site-specific reaction, is absent in the spectrum. Similarly, the peaks at $m / z$ 326.2, 493.1, and 761.0 in PD spectrum for [RLpTpSTpSSF $+\mathrm{H}]^{+}$(Figure

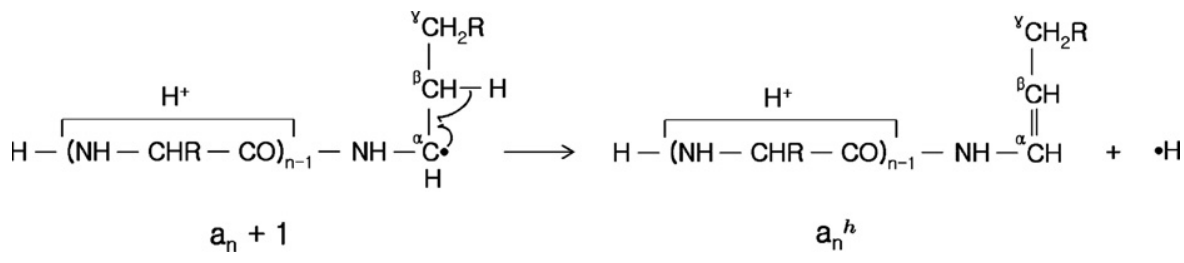

Scheme 1. Formation of $a_{n}^{h}$ from $a_{n}+1$. 


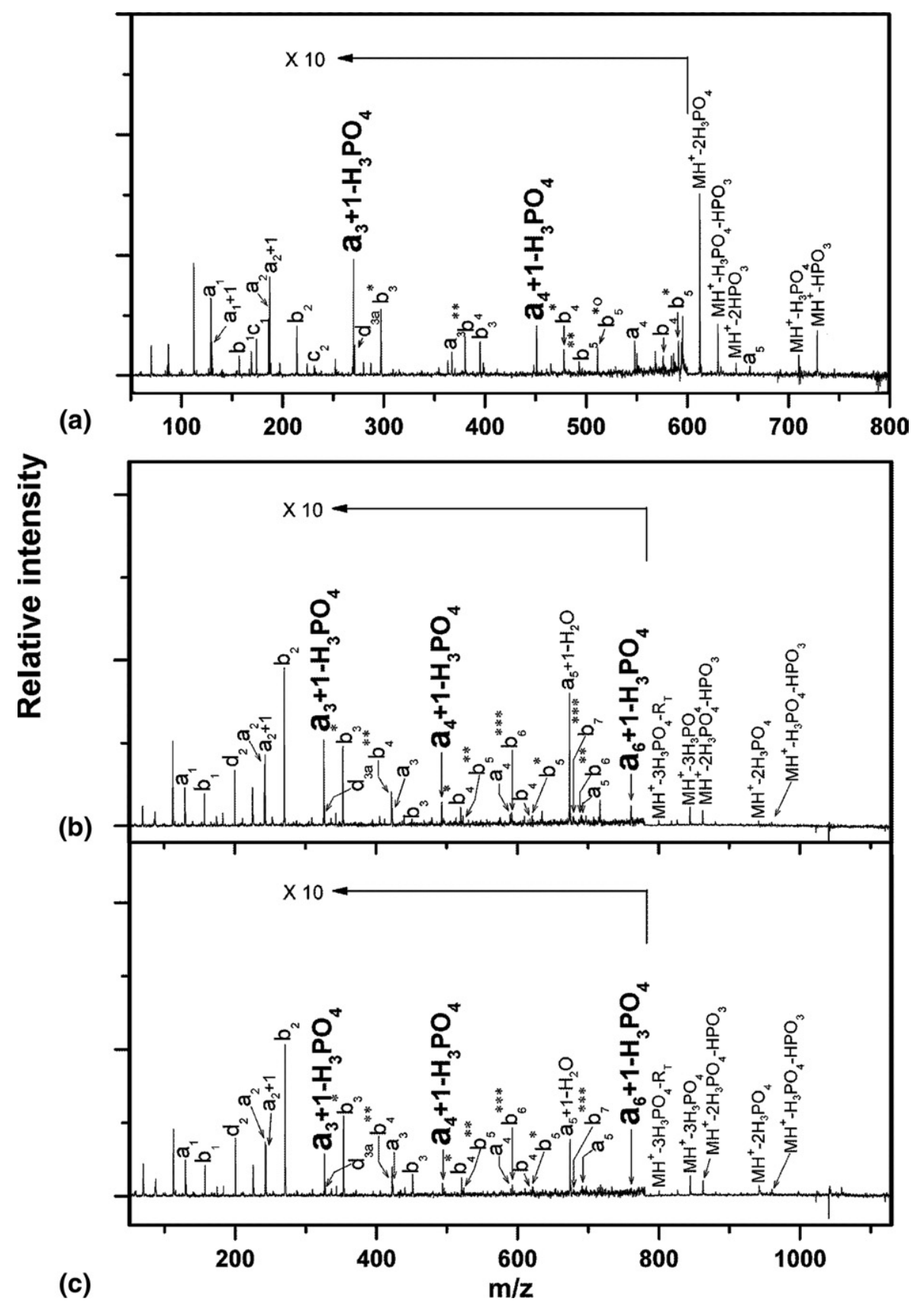

Figure 3. (a) $193 \mathrm{~nm}$ PD spectrum for [RGpTpTIT $+\mathrm{H}^{+}$, (b) $193 \mathrm{~nm}$, and (c) $266 \mathrm{~nm}$ PD spectra for $[\mathrm{RLpTpSTpSSF}+\mathrm{H}]^{+}$.

$3 b)$ are due to $\mathrm{a}_{3}+1-\mathrm{H}_{3} \mathrm{PO}_{4}, \mathrm{a}_{4}+1-\mathrm{H}_{3} \mathrm{PO}_{4}$, and $\mathrm{a}_{6}+1-\mathrm{H}_{3} \mathrm{PO}_{4}$, respectively. Here again, $\mathrm{a}_{5}-97$ and $a_{7}-97$ that can not be formed by the site-specific reaction are absent. We also recorded $266 \mathrm{~nm}$ PD spectrum for [RLpTpSTpSSF $+\mathrm{H}]^{+}$(Figure 3c). $\mathrm{a}_{\mathrm{n}}-97$ $(n=3,4$, and 6$)$ peaks appear in this spectrum also, even though with weaker intensities than in $193 \mathrm{~nm}$ PD, indicating that the mechanism for their formation is unaffected by the excited-state accessed by photoabsorption (amide backbone excitation at $193 \mathrm{~nm}$ versus aromatic side-chain excitation at $266 \mathrm{~nm}$ ).
$[\mathrm{KApSpSSG}+\mathrm{H}]^{+},{ }[\mathrm{HTpTTTK}+\mathrm{H}]^{+}$, and $[\mathrm{HTpTTTR}+\mathrm{H}]^{+}$

Lysine and histidine are weaker bases than arginine. For unphosphorylated peptide ions with lysine or histidine, but without arginine, it is well known that $\mathrm{C}_{\alpha}-\mathrm{CO}$ cleavages do not effectively compete with $\mathrm{b} / \mathrm{y}$ channels. Figure 4a shows 193 nm PD spectrum for $[\mathrm{KApSpSSG}+\mathrm{H}]^{+}$. Some $\mathrm{a}_{\mathrm{n}}$ ions appear prominently in this spectrum. A H/D exchange experiment showed that these ions were formed mostly via $b_{n}$, not via $a_{n}+$ 


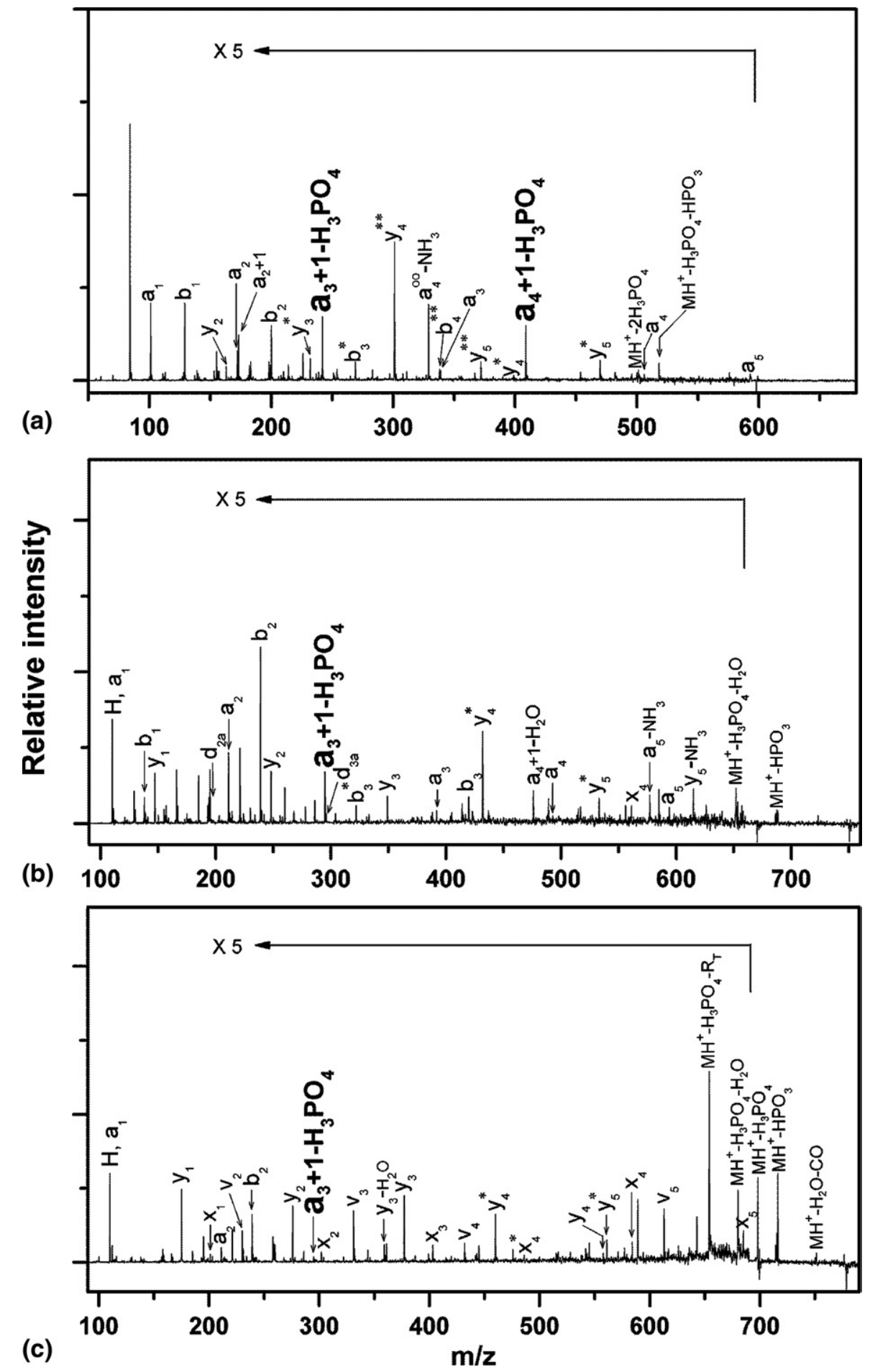

Figure 4. $193 \mathrm{~nm}$ PD spectra for (a) $[\mathrm{KApSpSSG}+\mathrm{H}]^{+},(\mathbf{b})[\mathrm{HTpTTTK}+\mathrm{H}]^{+}$, and (c) $[\mathrm{HTpTTTR}+\mathrm{H}]^{+}$.

1 , in agreement with the spectral correlation mentioned above. Similar trend was observed in PD of a phosphopeptide ion with histidine at the N-terminus, $[\mathrm{HTpTTT}+\mathrm{H}]^{+}$(spectrum shown in the Supplemental Data). In PD spectra for phosphopeptide ions with lysine or histidine at the N-terminus, however, $a_{n}-97$ ions formed by cleavage at phosphorylated residues appeared prominently, such as $a_{3}-97$ and $a_{4}-97$ in Figure $4 \mathrm{a} . \mathrm{H} / \mathrm{D}$ exchange experiments identified these as $\mathrm{a}_{\mathrm{n}}+1-\mathrm{H}_{3} \mathrm{PO}_{4}$. On the other hand, most of the peaks $\left(a_{n}+1, a_{n}^{h}\right.$ and $\left.a_{n}-97\right)$ traceable to $C_{\alpha}-C O$ cleavage at unphosphorylated residue appear in Figure 4a. That is, $\mathrm{C}_{\alpha}-\mathrm{CO}$ cleavages at phosphorylated residues effectively compete with $\mathrm{b} / \mathrm{y}$ channels, while 
those at unphosphorylated residues do not. $a_{n}-97$ peaks appear prominently even when lysine and/or histidine residues are present at both ends of a phosphopeptide ion, as demonstrated for [HTpTTTK $+\mathrm{H}]^{+}$ in Figure $4 b$. Namely, it seems that $a_{n}-97$ can be formed abundantly whenever there is a basic residue to the N-terminal side of a phosphorylated residue.

Observations presented so far suggest that one role of the basic residue at the N-terminus is to retain the additional (ionizing) proton such that the $\mathrm{N}$-terminal side product in $\mathrm{C}_{\alpha}-\mathrm{CO}$ cleavage appears as the charged species, viz. $a_{n}+1$. As a test, we recorded $193 \mathrm{~nm}$ PD spectrum (Figure 4c) for [HTpTTTR $+\mathrm{H}]^{+}$. Here again, $\mathrm{a}_{3}-97$ appears at $m / z$ 295.0. However, its intensity is very weak, in agreement with the fact that arginine is far more basic than histidine and hence can better retain the additional proton. For the same reason, $\mathrm{v}_{\mathrm{n}}, \mathrm{x}_{\mathrm{n}}, \mathrm{y}_{\mathrm{n}}$, and dephosphorylated sequence ions $\mathrm{x}_{\mathrm{n}}{ }^{*}$ and $\mathrm{y}_{\mathrm{n}}{ }^{*}$ dominate the spectrum. The same trend was observed for other phosphorylated peptide ions with arginine at the C-terminus, [VAAApSIR $+\mathrm{H}]^{+}$and $[\operatorname{VAATpSR}+\mathrm{H}]^{+}$, studied in a previous work [21]. $\mathrm{v}_{\mathrm{n}}$ and $\mathrm{x}_{\mathrm{n}}$ are presumably formed via $x_{n}+1$, which is the product of $\mathrm{C}_{\alpha}-\mathrm{CO}$ cleavage with charge retention at the C-terminus. Unlike phosphopeptide ions with a basic residue at the N-terminus, however, the site-specific dephosphorylation of $x_{n}+1-v i z$. formation of $x_{n}-97-$ was not observed in these cases.

\section{Discussion}

We have suggested that retaining the additional proton in the $\mathrm{N}$-terminal product of $\mathrm{C}_{\alpha}-\mathrm{CO}$ cleavage is an important role of the basic residue at the $\mathrm{N}$-terminus in this site-specific reaction. For phosphopeptide ions without any basic residue, the additional proton would be mobile and may have a finite chance to be at the N-terminal side of a phosphorylated residue. Then, site-specific formation of $a_{n}-97$ might occur in such cases also, just as for $[\text { HTpTTTK }+\mathrm{H}]^{+}$. To check such a possibility, we re-examined PD spectra for phosphopeptide ions without a basic residue ([ASSpSG + $\mathrm{H}]^{+},[\mathrm{GApSSSG}+\mathrm{H}]^{+}$, and $[\mathrm{TTpTVpTT}+\mathrm{H}]^{+}$) collected as a part of our previous study [21]. Indeed, site-specific $a_{n}-97$ peaks were found in such spectra also, but only as extremely weak peaks. This indicates that the basic residue at the $\mathrm{N}$-terminus is doing more than just retaining the additional proton. That is, it may not be a spectator but an active participant in $\mathrm{C}_{\alpha}-\mathrm{CO}$ cleavage, somehow making the reaction more efficient. For example, the additional proton attached to the basic residue might interact with the reaction center and make the $\mathrm{C}_{\alpha}-\mathrm{CO}$ bond more labile.

It has been mentioned that $\mathrm{C}_{\alpha}-\mathrm{CO}$ cleavage channels do not effectively compete with $b / y$ channels in highenergy dissociation of unphosphorylated peptide ions with lysine or histidine but without arginine. Even though the same trend was found to hold for phosphopeptide ions in this work, there was one notable exception, viz. efficient $\mathrm{C}_{\alpha}-\mathrm{CO}$ cleavage at the phosphorylated residue. To summarize, two conditions must be met for the specific $\mathrm{C}_{\alpha}-\mathrm{CO}$ cleavage, i.e., phosphorylation of the residue where the cleavage occurs and presence of a basic residue at the $\mathrm{N}$-terminus (or toward the $\mathrm{N}$-terminal side). It seems that the critical energy for $\mathrm{C}_{\alpha}-\mathrm{CO}$ cleavage gets smaller when these two conditions are met, even though how these conditions act is unclear.

We have also mentioned that the site-specific dephosphorylation of $x_{n}+1$-viz. formation of $x_{n}-$ 97-does not occur for phosphopeptide ions with arginine at the C-terminus even though $x_{n}+1$ is the dominant ionic product of $\mathrm{C}_{\alpha}-\mathrm{CO}$ cleavage in such cases. Let us consider $a_{n}+1$ phosphorylated at the C-terminal $\left(-\mathrm{pC}_{\alpha} \bullet\right)$ and $\mathrm{x}_{\mathrm{n}}+1$ phosphorylated at the N-terminal $\left(\bullet \mathrm{CO}-\mathrm{NH}-\mathrm{pC}_{\alpha}-\right)$, each formed by homolytic $\mathrm{C}_{\alpha}-\mathrm{CO}$ cleavage. Let us suppose that dephosphorylations of these radical cations are radical directed. Then, more efficient dephosphorylation of $a_{n}+1$ than $x_{n}+1$ may be attributed to the fact that the radical site in the former ion is closer to the phosphate substituent than in the latter. Or, prominence of $a_{n}-97$ together with absence of $x_{n}-97$ may be an indication that dephosphorylation of $a_{n}+1$ occurs by radical site initiation. We have found in the H/D exchange study that the hydrogen atom transferred to the phosphate group $\left(\mathrm{OPO}(\mathrm{OH})_{2}\right)$ is exchangeable. However, we do not know where this hydrogen is coming from and how it participates in the radical directed reaction, if it does.

Recently, Diedrich and Julian [28] reported site-specific radical directed dissociation of peptide ions at phosphorylated residue. Instead of studying intact phosphopeptides, $\mathrm{C}_{\beta}-\mathrm{OPO}(\mathrm{OH})_{2}$ bond was first cleaved, i.e., the phosphate group was eliminated, and then replaced by $\mathrm{C}_{\beta}-\mathrm{S}$ bond by addition of 2-naphthalenethiol. $266 \mathrm{~nm}$ photolysis of the derivatized peptide ions cleaved the $\mathrm{C}_{\beta}-\mathrm{S}$ bond and generated radical cations with naphthalenesulfide loss together with radical site-specific $a_{n}$ and $d_{n}$ ions. Even if the loss of $\mathrm{H}_{3} \mathrm{PO}_{4}$ from $\mathrm{a}_{\mathrm{n}}+1$ observed in the present work is radical directed, its mechanism would be different from the above because the radical positions are different, $C_{\alpha}$ in the present case versus $C_{\beta}$ in Diedrich and Julian's case.

\section{Conclusion}

Site-specific dissociation at phosphorylated residue found in the present work can be useful for the analysis of phosphopeptides, especially for pinpointing phosphorylated residues in multiply phosphorylated peptides with multiple serine/threonine residues. The fact that this reaction occurs for intact phosphopeptide ions can be particularly useful in this regard. Propensity of a phosphate substituent to make the adjacent $\mathrm{C}_{\alpha}-\mathrm{CO}$ bond more labile may also find interesting applications for the structural study of proteins. 


\section{Acknowledgments}

The authors acknowledge financial support for this work by Korea Research Foundation, Republic of Korea, and by the Bio-signal Analysis Technology Innovation program (M10645010002-06N450100,210) of the Ministry of Education, Science, and Technology (MEST), Republic of Korea. Y.S.S. thanks MEST for Brain Korea 21 Fellowship.

\section{Appendix A Supplementary Material}

Supplementary material associated with this article may be found in the online version at doi:10.1016/ j.jasms.2009.09.003.

\section{References}

1. Kinter, M.; Sherman, N. E. Protein Sequencing and Identification Using Tandem Mass Spectrometry; John Wiley: New York, 2000; pp 64-116, $238-268$.

2. Hernandez, P.; Muller, M.; Appel, R. D. Automated Protein Identification by Tandem Mass Spectrometry: Issues and Strategies. Mass Spectrom. Rev. 2006, 25, 235-254.

3. McLafferty, F. W. Tandem Mass Spectrometry; Wiley-Interscience: New York, 1983; pp 125-174.

4. Hillenkamp, F.; Karas, M.; Beavis, R. C.; Chait, B. T. Matrix-Assisted Laser Desorption Ionization Mass-Spectrometry of Biopolymers. Anal. Chem. 1991, 63, 1193A-1203A

5. Kebarle, P.; Ho, Y. On the Mechanism of Electrospray Mass Spectrometry. In Electrospray Ionization Mass Spectrometry, Cole, R.B., Ed.; WileyInterscience, New York, 1997; pp 3-64.

6. Spengler, B.; Kirsch, D.; Kafumann, R. Peptide Sequencing by MatrixAssisted Laser-Desorption Mass-Spectrometry. Rapid Commun. Mass Spectrom. 1992, 6, 105-108.

7. Cooks, R. G. Collision Spectroscopy; Plenum: New York, 1978; pp 357-450.

8. Dunbar, R. C. Photodissociation of Trapped Ions. Int. J. Mass. Spectrom. 2000, 200, 571-589.

9. Moon, J. H.; Yoon, S. H.; Kim, M. S. Photodissociation of Singly Protonated Peptides at $193 \mathrm{~nm}$ Investigated with Tandem Time-ofFlight Mass Spectrometry. Rapid Commun. Mass Spectrom. 2006, 20, 2201-2208.

10. Zubarev, R. A.; Kelleher, N. L.; McLafferty, F. W. Electron Capture Dissociation of Multiply Charged Protein Cations. A Nonergodic Process. J. Am. Chem. Soc. 1998, 120, 3265-3266.

11. Syka, J. E.; Coon, J. J.; Schroeder, M. J.; Shabanowitz, J.; Hunt, D. F. Peptide and Protein Sequence Analysis by Electron Transfer Dissocia- tion Mass Spectrometry. Proc. Natl. Acad. Sci. U.S.A. 2004, 101, 9528-9533.

12. Roepstorff, P.; Fohlman, J. Proposal for a Common Nomenclature for Sequence Ions in Mass-Spectra of Peptides. J. Biomed. Mass Spectrom. 1984, 11, 601

13. Biemann, K. Sequencing of Peptides by Tandem Mass Spectrometry and High-Energy Collision-Induced Dissociation. Methods in Enzymology, Vol. CXCIII. Mass Spectrometry; McCloskey, J. A., Ed.; Academic Press: New York, 1990; pp 455-479.

14. Hunter, T. Signaling-2000 and Beyond. Cell 2000, 100, 113-127.

15. Berg, J. M.; Tymoczko, J. L.; Stryer, L. Biochemistry, 5th ed.; Freeman: New York, 2002.

16. Wilm, M.; Neubauer, G.; Mann, M. Parent Ion Scans of Unseparated Peptide Mixtures. Anal. Chem. 1996, 68, 527-533.

17. Annan, R. S.; Carr, S. A. Phosphopeptide Analysis by Matrix-Assisted Laser Desorption Time-of-Flight Mass Spectrometry. Anal. Chem. 1996, $68,3413-3421$.

18. McLachlin, D. T.; Chait, B. T. Analysis of Phosphorylated Proteins and Peptides by Mass Spectrometry. Curr. Opin. Chem. Biol. 2001, 5, 591-602.

19. Bennett, K. L.: Stensballe, A.; Podtelejnikov, A. V.; Moniatte, M.; Jensen, O. N. Phosphopeptide Detection and Sequencing by Matrix-Assisted Laser Desorption/Ionization Quadrupole Time-of-Flight Tandem Mass Spectrometry. J. Mass Spectrom. 2002, 37, 179-190.

20. Chalmers, M. J.; Kolch, W.; Emmett, M. R.; Marshall, A. G.; Mischak, H Identification and Analysis of Phosphopeptides. J. Chromatogr. B 2004, $803,111-120$.

21. Moon, J. H.; Shin, Y. S.; Kim, M. S. Utility of Reaction Intermediate Monitoring with Photodissociation Multi-Stage $\left(\mathrm{MS}^{\mathrm{n}}\right)$ Time-of-Flight Mass Spectrometry for Mechanistic and Structural Studies: Phosphopeptides. Int. J. Mass Spectrom. 2009, in press.

22. Moon, J. H.; Yoon, S. H.; Kim, M. S. Construction of an Improved Tandem Time-of-Flight Mass Spectrometer for Photodissociation of Ions Generated by Matrix-Assisted Laser Desorption Ionization (MALDI). Bull. Korean Chem. Soc. 2005, 26, 763-768.

23. Yoon, S. H.; Moon, J. H.; Choi, K. M.; Kim, M. S. A Deflection System to Reduce the Interference from Post-Source Decay Product Ions in Photo Dissociation Tandem Time-of-Flight Mass Spectrometry. Rapid Commun. Mass Spectrom. 2006, 20, 2201-2208.

24. Yoon, S. H.; Kim, M. S. Development of a Time-Resolved Method for Photodissociation Mechanistic Study of Protonated Peptides: Use of a Voltage-Floated Cell in a Tandem Time-of-Flight Mass Spectrometer. J. Am. Soc. Mass Spectrom. 2007, 18, 1729-1739.

25. Yoon, S. H.; Chung, Y. J.; Kim, M. S. Time-Resolved Photodissociation of Singly Protonated Peptides with an Arginine at the N-Terminus: A Statistical Interpretation. J. Am. Soc. Mass Spectrom. 2008, 19, 645-655.

26. Neta, P.; Pu, Q.-L.; Yang, X.; Stein, S. E. Consecutive Neutral Losses of $\mathrm{H}_{2} \mathrm{O}$ and $\mathrm{C}_{2} \mathrm{H}_{4} \mathrm{O}$ from N-Terminal Thr-Thr and Thr-Ser in CollisionInduced Dissociation of Protonated Peptides Position Dependent Water Loss from Single Thr or Ser. Int. J. Mass Spectrom. 2007, 267, 295-301.

27. Johnson, R. S.; Martin, S. A.; Biemann, K. Collision-Induced Fragmentation of $(\mathrm{M}+\mathrm{H})^{+}$Ions of Peptides. Side-Chain Specific Sequence Ions. Int. J. Mass Spectrom. Ion Processes 1988, 86, 137-154.

28. Diedrich, J. K.; Julian, R. R. Site-Specific Radical Directed Dissociation of Peptides at Phosphorylated Residues. J. Am. Chem. Soc. 2008, 130, 12212-12213. 